\title{
A Suplementação de Creatina Prejudica a Função Renal?
}

\author{
Does Creatine Supplementation Harm Renal Function?
}

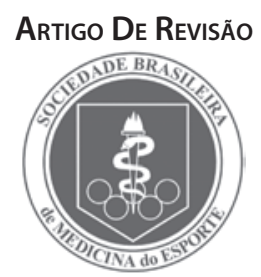

Bruno Gualano ${ }^{*}$

Carlos Ugrinowitsch ${ }^{1}$

Antonio Carlos Seguro ${ }^{2}$

Antonio Herbert Lancha Junior

1. Escola de Educação Física e Esporte - Universidade de São Paulo

2. Faculdade de Medicina

- Universidade de São Paulo

\section{Endereço para correspondência:} Avenida Professor Mello Moraes, 65. Butantã. 05508-900. São Paulo, SP. Brasil, telefone: 511130913096

Fax: 511130913136

E-mail: gualano@usp.br

Submetido em 14/02/2007

Versão final recebida em 27/08/2007 Aceito em 06/09/2007

\begin{abstract}
RESUMO
Enquanto o consumo de creatina por atletas e praticantes de atividade física tem crescido vertiginosamente, os efeitos adversos desse suplemento continuam sendo alvos de calorosos debates científicos, sobretudo no que se refere à função renal. O objetivo dessa revisão é descrever as falhas metodológicas e lacunas na literatura, que contribuem para a divergência do tema. Relatos de caso sugerem que a creatina é um potencial agente nefrotóxico. Em contrapartida, estudos longitudinais, embora possuam diversas limitações, indicam o oposto. Pesquisas com humanos não demonstram efeitos deletérios da suplementação de creatina à função renal, porém a falta de controle experimental e o caráter retrospectivo da maioria delas comprometem as conclusões dos autores. Já os estudos experimentais com ratos empregam bons marcadores de função renal e possuem controle de variáveis satisfatório. Contudo, os resultados destes são contraditórios. Estudos futuros devem investigar os efeitos da suplementação de creatina em diversas patologias renais, assim como em idosos, diabéticos do tipo 2 e hipertensos, cuja propensão a nefropatia é bem descrita. Não há evidências de que a suplementação de creatina prejudique a função renal em sujeitos saudáveis, quando consumida na dosagem preconizada. Diante disso, questiona-se a legitimidade científica da proibição do comércio de creatina no Brasil.
\end{abstract}

Palavras-chave: efeitos adversos, suplementos alimentares, creatinina, cistatina C, rim

\begin{abstract}
While creatine consumption has been greatly increasing among athletes and physical activity practitioners, the adverse effects of this supplement remain scientifically controversial, especially concerning renal function. The aim of this review is to describe the methodological limitations and gaps in the literature which contribute to the topic's divergence. Case reports suggest that creatine is a nephrotoxic agent. On the other hand, despite having several limitations, longitudinal studies have indicated the opposite. Research with humans does not demonstrate any deleterious effects as a consequence of creatine supplementation; however, the absence of experimental control as well as their retrospective characteristics compromise the authors' conclusion. Experimental studies with animal models though, use both gold standard for renal function and have satisfactory variable control. However, the results remain controversial. Future studies should investigate the effects of creatine supplementation in several kidneys diseases as well as in the elderly, type 2 diabetis and hypertensive individuals, whose tendency to renal dysfunction is well-described. There is not evidence that creatine supplementation causes renal deterioration in healthy subjects when it is ingested in the recommended dosage. Thus, we have some concerns about the sale prohibition of creatine supplementation in Brazil.
\end{abstract}

Keywords: adverse effects, food supplements, creatinine, cystatin C, kidney

\section{INTRODUÇÃO}

A creatina (ácido a-metil guanidino acético) é uma amina de ocorrência natural encontrada primariamente no músculo esquelético e sintetizada endogenamente pelo fígado, rins e pâncreas a partir dos aminoácidos glicina e arginina. Também pode ser obtida via alimentação, especialmente pelo consumo de carne vermelha e peixes. A produção endógena (1 g/dia) somada à obtida na dieta $(1 \mathrm{~g} /$ dia para uma dieta onívora) se iguala à taxa de degradação espontânea da creatina e fosfocreatina, formando creatinina, por reação não enzimática ${ }^{(1)}$. A creatina é encontrada no corpo humano nas formas livre (60 a 70\%) e fosforilada (30 a 40\%). Cerca de 95\% é armazenada no músculo esquelético, sendo que o restante se situa no coração, músculos lisos, cérebro e testículos ${ }^{(1,2)}$.

Desde que foi demonstrado que a suplementação de creatina
(20 g/dia por 5-7 dias) promove aumento de 20\% nas concentrações de creatina muscular ${ }^{(3)}$, diversos estudos investigaram o efeito da suplementação no rendimento esportivo. Atualmente, são bem documentados os efeitos ergogênicos da suplementação de creatina em atividades intermitentes de alta intensidade e curta duração (para mais detalhes, ver Terjung et al. ${ }^{(2)}$ ). Além disso, estudos recentes têm demonstrado que a suplementação de creatina pode ser benéfica em certos acometimentos neuromusculares ${ }^{(4,5)}$, doenças crônico-degenerativas $^{(6,7)}$ e tolerância à glicose ${ }^{(8)}$. Em contrapartida, as dúvidas acerca dos efeitos adversos dessa substância são inúmeras, sobretudo no que tange à função renal.

Os efeitos da suplementação de creatina sobre a função renal são debatidos intensamente na literatura científica. Enquanto alguns pesquisadores posicionam-se cautelosamente quanto ao uso dessa substância, uma vez que estudos de caso têm sugerido efeitos deletérios à 
função renal, há autores que se debruçam sobre estudos longitudinais, que embora possuam sérias limitações metodológicas, indicam a segurança da suplementação de creatina. Diante da incerteza em torno do tema, a mídia e os órgãos reguladores de cada país têm tomado suas próprias posições acerca dos riscos desse suplemento.

Esse trabalho tem o intuito de revisar os efeitos da suplementação de creatina na função renal, não apenas descrevendo resultados da literatura, mas também discutindo criticamente os principais fatores que contribuem para a divergência nas conclusões. Desta forma, especial enfoque será dado aos aspectos metodológicos dos estudos revisados, bem como às polêmicas posições da mídia e das agências reguladoras nesse assunto. Por fim, serão apontadas as lacunas que, de fato, existem na literatura e não permitem conclusões generalizadas sobre o tema.

Buscou-se descrever, nessa revisão, todos os artigos originais que tinham como objetivo direto a investigação dos efeitos da suplementação de creatina na função renal. Utilizou-se, para tanto, a base de dados Medline. Os termos empregados na busca foram: creatine supplementation and renal function, kidneys, renal dysfunction, adverse effects, deleterious effects. Além disso, estudos resumidos e cartas aos editores que, ao nosso ver, contribuiriam para o entendimento do tema, também foram incluídos.

\section{As posições da mídia e das agências reguladoras}

Exatamente três dias após os nefrologistas britânicos Pritchard e Kalra ${ }^{(9)}$ terem publicado um estudo de caso no periódico The Lancet, sugerindo haver "fortes evidências de que a creatina era responsável por deterioração na função renal" (esse trabalho será discutido no próximo tópico), a revista de esporte francesa L'Equipe ${ }^{(10)}$ alarmou seus leitores acerca do perigo da suplementação de cretina em quaisquer condições. Segundo Poortmans e Francaux ${ }^{(11)}$, essa notícia "bombástica" foi rapidamente repercutida por toda a Europa. Nesse período, foram atribuídos diversos efeitos deletérios à creatina, tais como disfunção renal, alterações hepáticas e até mesmo morte. De fato, os próprios pesquisadores Pritchard e Kalra ${ }^{(9)}$ contribuíram para isso, ao ligarem o consumo desse suplemento à morte de três lutadores de luta grecoromana. Atualmente, sabe-se que a creatina não esteve associada a esse episódio, já que investigações policiais concluíram que apenas um desses sujeitos suplementava com creatina ${ }^{(11)}$.

Importantes entidades como a US Food and Drog Administration $(\text { FDA })^{(11)}$, a Association of Professional Team Physicians ${ }^{(11)}$ e o American College of Sports Medicine (ACSM) ${ }^{(2)}$ atestam a segurança da creatina em curto prazo, apesar de ressaltarem que mais estudos devam investigar essa questão em longo prazo. O Comitê Olímpico Internacional (COI) liberou o consumo dessa substância, alegando que a mesma não era considerada droga, mas apenas suplemento alimentar.

Em contrapartida, alguns países, como a França, tomaram a frente da ciência e proibiram a venda desse suplemento. No Brasil, a Agência Nacional de Vigilância Sanitária (ANVISA), por meio da portaria nº 222 (24 de março de 1998), que discorre sobre as normas técnicas referentes a alimentos para praticantes de atividade física, surpreendentemente, não contemplou a creatina. A essa posição, tecemos duas críticas. A primeira se refere a sua natureza simplista e generalista em se taxar essa substância como "saudável ou não". Os suplementos hiperprotéicos (cuja comercialização é permitida no Brasil), por exemplo, não possuem riscos aparentes a sujeitos saudáveis. No entanto, a ingestão extra de proteína em insuficientes renais crônicos poderia ser prejudicial. Da mesma forma, é importante que se estabeleça a segurança da creatina nas mais diversas situações fisiopatológicas, ressaltando aquelas em que o consumo é livre de riscos. Outro problema dessa decisão consiste na capacidade de formar opinião, entre os leigos e especialistas, que ela carrega consigo. Não raras vezes essa proibição é vista como status quo, ou seja, uma prova irrefutável do potencial risco da creatina à saúde. Dessa maneira, a evidência científica assume lugar secundário frente às alegações da mídia, bem como das imposições das agências reguladoras, numa clara inversão de papéis.

É comum observar inúmeros especialistas da área de saúde condenando, veementemente, o consumo de creatina, sobretudo com a alegação de que esse suplemento é prejudicial à função renal. A dedução é simples e até mesmo lógica: a creatina é convertida espontaneamente a creatinina, a qual é excretada pelos rins. O excesso de creatina obtida pela suplementação geraria uma sobrecarga renal ao ser excretada. Nos próximos tópicos, verificaremos se os estudos científicos que investigaram essa premissa corroboraram a teoria inicial.

\section{Estudos de caso - o início da polêmica}

Kuehl et al. ${ }^{(12)}$ foram os primeiros a relacionar a suplementação de creatina à insuficiência renal. Os autores atribuíram ao consumo regular de creatina (10g/dia por 3 meses) o quadro de dispnéia, perda de peso e fadiga relatado por um jogador de futebol americano asmático. Testes laboratoriais indicavam creatinina (Crn) sérica de 1,7 mg/dl, enquanto que valores de clearance de creatinina (ClCrn), amônia, sódio, potássio e análises da urina foram considerados normais. Após 1 mês de suspensão da suplementação e tratamento com $\beta$ agonistas e esteróides aerolizados, verificou-se redução da $\mathrm{Crn}(1,3 \mathrm{mg} / \mathrm{dl})$ e desaparecimento dos sintomas. As críticas a esse trabalho fundamentaram-se no polêmico diagnóstico de insuficiência renal proposto pelos autores, tendo em vista que todos os parâmetros de função renal estavam normais, com exceção da Crn. Sabe-se que a Crn per se pode não ser um bom indicador de disfunções renais em sujeitos suplementados com creatina, já que está sujeita à interferências de massa muscular, treinamento físico e da própria suplementação. Nesse caso, não se pode descartar a possibilidade de um caso falso positivo.

Nesse mesmo ano, Pritchard e Kalra ${ }^{(9)}$ apresentaram um estudo de caso de um homem de 25 anos com glomeruloesclerose há oito anos e periódicas síndromes nefróticas, tratadas com ciclosporina há cinco anos. Durante esse tempo, a função renal estava normalizada. Contudo, testes futuros revelaram crescente deterioração da função renal, com elevação de $\mathrm{Crn}$ e queda de $\mathrm{ClCrn}$. O paciente informou que estava consumindo creatina nos últimos dois meses ( $5 \mathrm{~g} /$ dia na primeira semana seguidos por $2 \mathrm{~g}$ /dia por sete semanas). A suplementação foi suspensa a fim de recuperar a filtração glomerular. Um mês após, observou-se a normalização da função renal. Os autores afirmaram haver fortes indícios que a suplementação de creatina era responsável pela deterioração renal. Devemos observar tal trabalho com cautela, uma vez que o paciente apresentava doença renal anterior ao uso de creatina. Além disso, ressalta-se que a baixa dose de creatina suplementada durante o período de manutenção (2g/dia) assemelha-se à quantidade consumida diariamente nos alimentos somada a produção endógena, razão pela qual as conclusões dos autores estariam equivocadas. Infelizmente, os autores não providenciaram dados de ingestão ou excreção de creatina.

Koshy et al. ${ }^{(13)}$ indicaram a suplementação de creatina como causadora de nefrite intersticial aguda e injúria tubular focal, em um homem de 25 anos aparentemente saudável. Esse sujeito apresentou aumento nas concentrações séricas de creatinina $(2,3 \mathrm{mg} / \mathrm{dl}$ ) e pressão sanguínea 160/100. Infelizmente, os autores não forneceram maiores informações acerca do histórico clínico do sujeito.

Barisic et al. ${ }^{(14)}$ empregaram, com sucesso, a suplementação de creatina (20g/dia durante 12 dias, seguidos por 5/g/dia ao longo de 28 meses) no tratamento de um jovem de 18 anos com encefalopatia mitocondrial. Apesar da melhora observada no quadro psicomental do sujeito, os autores relataram deterioração na função renal após 28 meses de intervenção, conforme indicado pela redução no $\mathrm{ClCrn}$ e retenção 
de uréia. Barisic et al. ${ }^{(14)}$ ressaltaram, no entanto, que o paciente sofria de insuficiência renal moderada desde os 15 anos (clearance de EDTA: $28 \mathrm{ml} / \mathrm{min} / 1,73 \mathrm{~m}^{3}$; fluxo sanguíneo renal: $333 \mathrm{ml} / \mathrm{min}$; proteinúria: 2,3/ dia). Diante disso, acreditam que a deterioração verificada ao longo do tratamento seja "devido mais ao próprio curso natural (da insuficiência renal pré-existe) do que em função da suplementação de creatina".

Revai et al. ${ }^{(15)}$ relataram um caso no qual um indivíduo de 22 anos de idade, usuário de esteróide anabólico (metandiona) e creatina em grande quantidade (200 g/dia) apresentava glomerulonefrite membranoproliferativa difusa do tipo I. Os autores sinalizaram para o risco da suplementação de creatina em acometimentos renais. Entretanto, a vertiginosa dose de creatina ingerida cronicamente pelo sujeito, bem como o uso de esteróides anabolizantes, potencial causador de nefropatias, comprometem as conclusões dos autores.

Thorsteinsdottir et al. ${ }^{(16)}$ atribuíram à suplementação de creatina (15g/semana durante 6 semanas) o quadro de insuficiência renal aguda e nefrite intersticial aguda, em um homem de 24 anos. Quando se apresentou ao hospital, esse sujeito demonstrou reduzido $\mathrm{ClCrn}(30 \mathrm{ml} / \mathrm{min})$, retenção de uréia $(30 \mathrm{mg} / \mathrm{dl})$ e Crn e proteinúria elevadas $(3,8 \mathrm{mg} / \mathrm{dl}$ e $386 \mathrm{mg} / 24$ horas, respectivamente). A inflamação intersticial foi diagnosticada por meio de biópsia renal. O paciente foi hospitalizado e orientado a deixar de consumir todos suplementos nutricionais. Após 5 dias, a função renal foi normalizada e a proteinúria cessou. Apesar dos inúmeros suplementos ingeridos pelo sujeito, os autores acreditam que o agente nefrotóxico tenha sido a creatina, já que não encontraram na literatura evidências que apontem para outras substâncias consumidas. Entretanto, não podem ser descartados os efeitos do consumo simultâneo desses suplementos, bem como a possibilidade de contaminação, por adulterantes ou impurezas, de alguns deles. Além disso, salientamos o fato de que a dosagem de creatina consumida pelo sujeito era praticamente a mesma de um indivíduo saudável não vegetariano. Os pesquisadores argumentaram que a nefrite intersticial aguda não é dose-dependente, porém admitem que, diante do pequeno número de casos na literatura, a suplementação de creatina tem baixo poder nefrotóxico. Mesmo assim, propõem que a nefrite intersticial induzida por creatina seja um diagnóstico diferencial em insuficiências renais agudas em atletas.

Em suma, os diversos relatos de caso (sintetizados na tabela 1) apontam para o potencial efeito nefrotóxico da creatina. As críticas a esses estudos remetem-se às audaciosas generalizações dos autores. Estudos de caso retrospectivos não permitem generalizações de resultados. Eles podem, no máximo, apontar que é preciso ter cuidado na utilização da suplementação de creatina. Contudo, o crescente número de casos na literatura despertou o interesse da comunidade científica, que elaborou modelos experimentais mais precisos com o intuito de responder tal questão.

\section{Estudos quase-experimentais e experimentais - limitações, críticas e mais contradições}

Poucos estudos com esses modelos foram desenvolvidos em relação ao tema. Didaticamente, descreveremos aqueles com humanos (sintetizados na tabela 2) primeiramente e, em seguida, com animais (sintetizados na tabela 3).

\section{Estudos com humanos}

Poortmans et al. ${ }^{(19)}$ foram os pioneiros na busca de métodos sistemáticos para a avaliação da função renal em sujeitos suplementados com creatina. Os pesquisadores suplementaram cinco sujeitos saudáveis com creatina (20 g/dia por cinco dias) ou placebo em um modelo crossover. Análises de creatina e Crn urinária e plasmática foram realizadas após cada sessão experimental. A albuminúria e a proteinúria também foram avaliadas. Os resultados revelaram que, a despeito do aumento das concentrações sérica e urinária de creatina, as concentrações de Crn, ClCrn, taxa de excreção de albumina e proteína permaneceram inalterados. Os autores afirmaram que a suplementação aguda de creatina não tem efeito na função renal. A reduzida amostra desse estudo pode ser considerada uma grave limitação. Além disso, a ausência de marcadores mais precisos (padrão-ouro) não permite maiores conclusões.

A mesma equipe de pesquisa investigou o efeito crônico da suplementação de creatina na função renal. De maneira retrospectiva, os autores determinaram o ClCrn, albumina e uréia em usuários (dez meses a cinco anos) ou não de creatina. Os resultados não demonstraram diferenças significantes entre os grupos. Diante disso, os autores concluíram que a suplementação de creatina, em médio e longo prazo, também não afetava a função renal ${ }^{(20)}$. Kuhel et al. ${ }^{(21)}$ criticaram severamente os resultados e conclusão desse estudo, salientando as ausências de aleatorização dos grupos, de marcadores precisos de função renal e de padronização da suplementação, bem como o baixo poder estatístico, já que apenas um sujeito do estudo consumia doses acima de 10g/dia. Além disso, o fato de que o grupo controle era formado por 85 estudantes universitários, enquanto que o grupo suplementado com creatina era composto por 9 atletas profissionais de diversas modalidades, aponta a total heterogeneidade da amostra. Em virtude dessas limitações, Kuehl et al. ${ }^{(21)}$ concluíram que não há evidências suficientes para se afirmar que a suplementação de creatina não prejudica a função renal.

Tabela 1. Estudos de caso que associaram danos renais à suplementação de creatina.

\begin{tabular}{|c|c|c|c|c|c|}
\hline Autores & Características do sujeito & $\begin{array}{l}\text { Regime de } \\
\text { suplementação }\end{array}$ & $\begin{array}{l}\text { Avaliação da } \\
\text { função renal }\end{array}$ & $\begin{array}{l}\text { Uso de outras drogas ou } \\
\text { suplementos? Quais? }\end{array}$ & $\begin{array}{c}\text { Doença renal } \\
\text { pré-existente? Qual? }\end{array}$ \\
\hline Kuehl et al. 1998 & $\begin{array}{l}\text { Jogador de futebol americano } \\
\text { asmático de } 19 \text { anos }\end{array}$ & 10g/dia por 3 meses & $\mathrm{Crn}^{*}$ & Albuterol & não \\
\hline Pritchard e Kalra 1998 & $\begin{array}{c}\text { Homem de } 25 \text { anos, praticante } \\
\text { de futebol }\end{array}$ & $\begin{array}{l}5 \mathrm{~g} / \text { dia na } 1 \text { a semana }+ \\
2 \mathrm{~g} / \mathrm{dia} \text { por } 7 \text { semanas }\end{array}$ & $\begin{array}{l}\text { Crn, } \mathrm{ClCrn} \text {, } \\
\text { isotópico }\end{array}$ & Não relatado & $\begin{array}{l}\text { Glomeruloescle-rose e } \\
\text { síndromes nefróticas }\end{array}$ \\
\hline Koshy et al. 1999 & Homem saudável de 20 anos & $5 \mathrm{~g} /$ dia por 4 semanas & $\mathrm{Cr}$, proteinúria, & Não relatado & não \\
\hline Barisic et al. 2002 & $\begin{array}{l}\text { Homem sedentário de } 18 \text { anos } \\
\text { com síndrome de MELAS** }\end{array}$ & $\begin{array}{l}\text { 20g/dia por } 12 \text { dias }+ \\
\text { 5/g/dia ao por } 28 \text { meses }\end{array}$ & $\begin{array}{l}\text { Crn, ClCrn, uréia } \\
\text { plasmática }\end{array}$ & Não relatado & Doença renal crônica \\
\hline Revai et al. 2003 & $\begin{array}{c}\text { Homem de } 22 \text { anos praticante } \\
\text { de musculação }\end{array}$ & 200g/dia cronicamente & Não relatado & Metandiona & não \\
\hline $\begin{array}{l}\text { Thorsteinsdottir et } \\
\text { al. } 2006\end{array}$ & $\begin{array}{c}\text { Homem de } 24 \text { anos praticante } \\
\text { de musculação }\end{array}$ & $\begin{array}{l}15 \mathrm{~g} / \text { semana por } 6 \\
\text { semanas }\end{array}$ & $\begin{array}{l}\text { Crn, ClCrn, uréia } \\
\text { plasmática }\end{array}$ & $\begin{array}{l}\text { Aminoácidos, vitaminas } \\
\text { e suplementos a base de } \\
\text { extratos vegetais ou não }\end{array}$ & não \\
\hline
\end{tabular}

Em todos os trabalhos, apenas 1 sujeito foi estudado. * o diagnóstico de deterioração da função renal foi embasado apenas nesse marcador, já que os demais não demonstraram alterações. ${ }^{* *}$ miopatia mitocondrial, encefalopatia, acidose lática e episódios AVC-símile. Abreviaturas: Crn: creatinina; ClCrn: clearance de creatinina 
Tabela 2. Pesquisas com humanos que estudaram efeitos da suplementação de creatina na função renal.

\begin{tabular}{|c|c|c|c|c|c|c|}
\hline Autores & $\mathbf{n}$ & Características da amostra & $\begin{array}{c}\text { Regime de } \\
\text { suplementação }\end{array}$ & $\begin{array}{l}\text { Avaliação da } \\
\text { função renal }\end{array}$ & Principais limitações & $\begin{array}{l}\text { Prejudicou a } \\
\text { função renal? }\end{array}$ \\
\hline Portmans et al. 1997 & 5 & Homens saudáveis & 20g/dia por 5 dias & $\begin{array}{l}\text { Crn, ClCrn, micro } \\
\text { albuminúria, } \\
\text { proteinúria }\end{array}$ & $\begin{array}{l}\text { baixo poder estatístico, } \\
\text { ausência de marcador padrão-ouro }\end{array}$ & não \\
\hline $\begin{array}{l}\text { Poortmans e } \\
\text { Francaux } 1999\end{array}$ & $94^{*}$ & Atletas de diversas modalidades & $\begin{array}{l}\text { De } 2 \text { a } 30 \mathrm{~g} / \text { dia por } 10 \\
\text { meses a } 5 \text { anos }\end{array}$ & $\begin{array}{c}\mathrm{Crn}, \mathrm{ClCrn}, \text { Clalb, } \\
\mathrm{ClCr}\end{array}$ & $\begin{array}{c}\text { Baixo poder estatístico e controle } \\
\text { de variáveis }\end{array}$ & não \\
\hline Robinson et al. 2000 & 48 & $\begin{array}{l}\text { Homens e mulheres saudáveis, } \\
\text { submetidos ou não a } \\
\text { treinamento de força }\end{array}$ & $\begin{array}{l}\text { 3g/dia por } 1 \text { semana }+ \\
\text { 20g/dia por } 8 \text { semanas }\end{array}$ & $\begin{array}{l}\text { Crn, uréia, sódio e } \\
\text { potássio plasmáticos }\end{array}$ & $\begin{array}{c}\text { Ausência de marcador padrão- } \\
\text { ouro, tratamento estatístico } \\
\text { empregado }\end{array}$ & não \\
\hline Kreider et al. 2003 & $98^{* *}$ & $\begin{array}{l}\text { Atletas profissionais de futebol } \\
\text { americano }\end{array}$ & $\sim 5 \mathrm{~g} /$ dia por 21 meses & $\mathrm{Crn}, \mathrm{ClCrn}$ & $\begin{array}{l}\text { Baixo controle de variáveis e } \\
\text { ausência de padrão-ouro }\end{array}$ & não \\
\hline Groeneld et al. 2005 & 310 & $\begin{array}{c}\text { Pacientes com esclerose } \\
\text { amiotrófica lateral }\end{array}$ & 10g/dia por 131 dias & $\begin{array}{l}\text { Crn, uréia sérica, } \\
\text { micro albuminúria }\end{array}$ & $\begin{array}{c}\text { Ausência de marcador padrão- } \\
\text { ouro, resultados limitados a } \\
\text { sujeitos com tal patologia }\end{array}$ & não \\
\hline $\begin{array}{l}\text { Poortmans et al. } \\
2005\end{array}$ & 20 & Homens saudáveis & $21 \mathrm{~g} / \mathrm{d}$ por 14 dias & $\begin{array}{l}\mathrm{ClCr}, \mathrm{Crn} \text {, micro } \\
\text { albuminúria }\end{array}$ & Baixo controle de variáveis & não*** \\
\hline Gualano et al. 2006 & 14 & $\begin{array}{c}\text { Homens saudáveis submetidos a } \\
\text { treinamento aeróbio }\end{array}$ & $\sim 10 \mathrm{~g} /$ dia por 3 meses & Cistatina C, Crn & $\begin{array}{c}\text { Ausência de grupo controle não } \\
\text { treinado }\end{array}$ & não \\
\hline
\end{tabular}

*dos quais apenas 9 foram suplementados com creatina; ** dos quais apenas 17 foram suplementados de 12 a 21 meses; *** houve aumento na formação de compostos citotóxicos. A classificação "baixo controle de variáveis" refere-se à ausência de aleatorização inicial, controle por placebo, dosagens pré-determinadas de suplementação e/ou amostras heterogêneas. Abreviaturas: $\mathrm{Crn}$ - creatinina plasmática; ClCrn - clearance de creatinina; Clalb - clearance de albumina; $\mathrm{ClCr}$ - clearance de creatina.

Tabela 3. Estudos experimentais com modelo animal.

\begin{tabular}{|c|c|c|c|c|c|c|}
\hline Autores & $\mathrm{n}$ & Características da amostra & $\begin{array}{c}\text { Regime de } \\
\text { suplementação }\end{array}$ & $\begin{array}{l}\text { Marcadores de função } \\
\text { renal }\end{array}$ & Principais limitações & $\begin{array}{c}\text { Prejudicou a função } \\
\text { renal? }\end{array}$ \\
\hline $\begin{array}{c}\text { Edmunds et al. } \\
2001\end{array}$ & 47 & Ratos Han:SPRD-cy* & $\begin{array}{c}2 \mathrm{~g} / \mathrm{Kg} \text { da dieta por } 7 \text { dias } \\
+0,48 \mathrm{~g} / \mathrm{kg} \text { da dieta por } \\
35 \text { dias }\end{array}$ & Crn, ClCrn, uréia plasmática & $\begin{array}{l}\text { A creatina não era pura, } \\
\text { ausência de padrão-ouro }\end{array}$ & $\begin{array}{l}\text { Sim. Além de acelerar a } \\
\text { progressão da doença } \\
\text { renal policísitca }\end{array}$ \\
\hline $\begin{array}{l}\text { Taes et al. } \\
2002\end{array}$ & 43 & $\begin{array}{l}\text { Ratos Wistar nefrectomizados } \\
\text { (2/3) e falso-operados }\end{array}$ & $2 \%$ dieta por 4 semanas & $\begin{array}{l}\text { cistatina C, Clinu, Cluréia, } \\
\text { ClCrn, Clalb, proteinúria }\end{array}$ & $\begin{array}{c}\text { Não foram investigados } \\
\text { efeitos em médio e longo } \\
\text { prazo }\end{array}$ & não \\
\hline $\begin{array}{l}\text { Ferreira et al. } \\
2005\end{array}$ & 36 & $\begin{array}{l}\text { Ratos Wistar submetidos ou } \\
\text { não a treinamento aeróbio }\end{array}$ & $\begin{array}{c}2 \mathrm{~g} / \mathrm{kg} \text { da dieta por } 10 \\
\text { semanas }\end{array}$ & $\begin{array}{l}\text { clearances de inulina e } \\
\text { paraminohipu-rato }\end{array}$ & $\begin{array}{l}\text { Pureza da creatina não } \\
\text { determinada }\end{array}$ & $\begin{array}{c}\text { Sim. Apenas nos ratos } \\
\text { não treinados }\end{array}$ \\
\hline
\end{tabular}

* modelo de doença renal policística. Abreviaturas: Crn - creatinina plasmática; ClCrn - clearance de creatinina, Clalb - clearance de albumina; Cluréia - clearance de uréia,

Clinu - clearance de inulina.

Robinson et al. ${ }^{(22)}$ investigaram possíveis efeitos deletérios da suplementação de creatina em homens e mulheres, utilizando-se de 26 parâmetros clínicos. Os autores dividiram a amostra, composta por 48 sujeitos fisicamente ativos, em 7 grupos, com o objetivo de avaliar distintamente os protocolos de "carregamento" de creatina (20g/dia durante por 5 dias) e "manutenção" (20g/dia durante por 5 dias seguidos por $3 \mathrm{~g} / \mathrm{dia}$ ao longo de 8 semanas). Os sujeitos submetidos ao protocolo de "carregamento" foram avaliados após 1 dia ou 6 semanas do término da suplementação. Já os indivíduos submetidos ao protocolo de "manutenção" foram subdivididos em grupos que realizavam ou não treinamento de força. Os pesquisadores consideraram que a suplementação de creatina não apresentou efeitos deletérios. Contudo, foram documentados aumentos nas concentrações de uréia e $\mathrm{Crn}$, nos grupos suplementados com creatina por 5 dias e 8 semanas, respectivamente. Os autores interpretaram essas alterações como de "baixa relevância clínica", citando, sobretudo, as limitações da Crn como marcador da taxa de filtração glomerular. Curiosamente, os pesquisadores utilizaram apenas Crn, sódio, potássio e uréia plasmáticos para avaliação de função renal e, mesmo diante da reconhecida imprecisão desses métodos (por parte da própria equipe de pesquisa), concluíram que a suplementação de creatina não apresenta riscos evidentes à função renal. Uma clara limitação do estudo se refere ao tratamento estatístico empregado. O teste t de Student pareado e não pareado foi aplicado para as comparações intra e interindividuais, respectivamente, quando a análise de variância seria mais adequada para o modelo do estudo.

Kreider et al. ${ }^{(23)}$ desenvolveram estudo retrospectivo com o objetivo de investigar os efeitos crônicos da creatina na função renal. Noventa e oito atletas profissionais de futebol americano receberam creatina de maneira denominada pelos próprios autores como "open label"(os voluntários escolhiam consumir ou não o suplemento, bem como a quantidade e o tempo de consumo) e, ao final do estudo, foram categorizados em usuários de creatina por zero a seis meses $(n=12)$, sete a 12 meses ( $n=25), 12$ a 21 meses ( $n=17)$ e não usuários de creatina ( $n=44)$. Todos os voluntários foram avaliados em 69 parâmetros clínicos, incluindo marcadores de função renal, como $\mathrm{Crn}$ e $\mathrm{ClCrn}$, em diversas fases do treinamento. Nenhuma diferença significativa foi encontrada entre os consumidores de creatina e grupo controle, razão pela qual os autores concluíram que, em atletas submetidos a treinamento intenso, a suplementação de creatina parece não afetar nenhum parâmetro clínico. Novamente, as críticas a esse trabalho remetem-se à ausência de distribuição aleatória dos grupos e marcadores precisos para avaliação da função renal, dosagens padronizadas de creatina, e limitação dos resultados a atletas de alto nível. 
Groeneveld et al. ${ }^{(24)}$ investigaram os efeitos da suplementação de creatina na função renal de sujeitos com esclerose lateral amiotrófica. Os pesquisadores dividiram os sujeitos em dois grupos, suplementados com creatina (10g/dia por 310 dias) ou placebo. Nenhuma diferença significante foi observada para os marcadores de função renal. Os autores, no entanto, verificaram aumento nas concentrações de creatinina no grupo suplementado, constatada por teste enzimático. A justificativa da equipe de pesquisa se refere à suposta interferência da ingestão de creatina nesse método. De fato, os pesquisadores não encontraram diferenças entre os grupos quando a mensuração de creatinina foi refeita em uma parcela da amostra, por meio de HPLC (High Performance Liquid Chromatograph), técnica que não sofre interferência da creatina. Esses resultados foram suportados por outros marcadores indiretos de função renal que não sofreram alterações, tais como micro albuminúria e uréia sérica. Infelizmente, os dados limitam-se à pacientes com esse acometimento neurológico. Além disso, destaca-se a falta de marcador preciso de função renal.

Com o objetivo de verificar se a suplementação de creatina aumenta a formação de compostos citotóxicos, Poortmans et al.(25) suplementaram 20 homens saudáveis ( $21 \mathrm{~g} /$ dia por 14 dias) e avaliaram a concentração urinária de formaldeído, metilamina e formato antes e após a intervenção. Os resultados indicam aumentos substanciais nas concentrações de formaldeído (4,5 vezes) e metilamina (9,2 vezes). Entretanto, dados de função renal ( $\mathrm{Cl}$ Crn, Crn e albumina urinária) não foram alterados. Os autores concluem que a despeito da formação de compostos citotóxicos em razão da suplementação de creatina, a função renal é preservada. No entanto, esse estudo deve ser visto com grande cautela, tendo em vista as ausências de marcadores precisos de função renal e grupo controle. Estudos controlados devem elucidar a relevância desses metabólitos na fisiopatologia renal, sobretudo em longo prazo.

Os estudos envolvendo humanos não verificaram alterações na função renal decorrentes da suplementação de creatina. Contudo, estes apresentam grandes limitações metodológicas, dentre as quais, destacam-se: falta de aleatorização amostral e grupo controle, baixo poder estatístico e ausência de marcadores precisos de função renal.

\section{Estudos com animais}

Edmunds et al. ${ }^{(28)}$ foram os primeiros a investigar o efeito da creatina na função renal por meio de estudo controlado prospectivo. Os autores utilizaram ratos Han:Sprague Dawley (SPRD-cy), modelo bem aceito de doença renal policística. Estes foram divididos em grupos controle e creatina $(2 \mathrm{~g} / \mathrm{Kg}$ da dieta por sete dias, seguidos por $0,48 \mathrm{~g} / \mathrm{kg}$ da dieta por 35 dias). Ressalta-se que a creatina desse estudo foi combinada a glutamina (5:1). Os resultados indicaram que o grupo creatina, comparado ao controle, apresentou piora na função renal, conforme evidenciado pela diminuição do ClCrn, aumento da Crn (apenas nos machos) e retenção de uréia. Além disso, a creatina provocou a progressão da doença renal policística, já que os ratos desse grupo tiveram valores maiores de peso renal, conteúdo de fluido renal e scores císticos. Os autores sugerem, frente aos achados, cautela ao se administrar creatina, principalmente em indivíduos com doença renal pré-existente.

Taes et al. ${ }^{(26)}$ também investigaram o efeito da suplementação de creatina quando da doença renal pré-existente. Para tanto, utilizaram ratos com insuficiência renal induzida pela remoção cirúrgica de 2/3 do tecido renal. Foram formados quatro grupos: falso-operados controle $(n=10)$, falso-operados creatina $(n=10), 2 / 3$ nefrectomizados controle $(n=12)$ e $2 / 3$ nefrectomizados creatina $(n=11)$. Depois de quatro semanas de intervenção, os dados de cistatina c, inulina, clearance de uréia, de creatinina e de albumina e excreção urinária de proteína não sofreram efeito da suplementação de creatina, tanto nos ratos nefrectomizados quanto nos falso-operados. Os autores concluem, portanto, que a suplementação de creatina não causa danos à função renal, mesmo havendo doença renal pré-existente. A divergência nos achados de Taes et al. ${ }^{(26)}$ e Edmunds et al. ${ }^{(28)}$ pode ser explicada pelas diferenças de modelo experimental, marcadores de função renal e pureza da suplementação de creatina.

Ferreira et al. ${ }^{(27)}$ investigaram os efeitos da suplementação de creatina em ratos saudáveis submetidos ou não a treinamento. Nesse trabalho, quatro grupos foram estudados por 10 semanas: creatina + exercício $(\mathrm{Cr}+\mathrm{E})$; creatina isolada $(\mathrm{Cr})$; placebo + exercício $(\mathrm{PI}+\mathrm{E})$; placebo isolado (PI). Somente o grupo $\mathrm{Cr}$ apresentou deterioração na filtração glomerular e no fluxo plasmático renal, avaliados por meio de clearances de inulina e paraminohipurato, respectivamente. Uma vez que o grupo $\mathrm{Cr}+\mathrm{E}$ não apresentou diminuição de filtração glomerular e fluxo plasmático renal, é possível que o exercício concomitante à suplementação possa ter minimizado os efeitos deletérios da creatina, prevenindo uma vasoconstrição. Outra possibilidade aventada pelos pesquisadores é que a contração muscular promova maior utilização do substrato no músculo, diminuindo a produção e excreção de creatinina. Em relação aos efeitos deletérios observados, duas hipóteses são assumidas pelos autores: diminuição do fluxo sanguíneo renal em função de vasoconstrição ou formação de produtos citotóxicos provenientes do metabolismo da creatina, tais como metilamina e formaldeído. Os autores alertam para os riscos da suplementação irrestrita de creatina, principalmente em longo prazo. Interessantemente, os achados desse estudo são opostos àqueles encontrados por Taes et al. (26). Um fator que pode ter contribuído para essa discrepância é a presença de traços de contaminantes na creatina administrada. Taes et al. ${ }^{(26)}$ declararam que a creatina empregada em seu trabalho possuía grau de pureza maior que $99 \%$. Em contrapartida, Ferreira et al. ${ }^{(27)}$ não realizaram teste de pureza em seu estudo.

Os estudos com modelos animais apresentam controle experimental satisfatório, bem como marcadores precisos de função renal. Entretanto, ao contrário do esperado, os resultados permanecem conflitantes, fomentando a polêmica em torno do tema.

\section{Lacunas na literatura}

A partir de agora, será dada particular atenção às perguntas que ainda não foram respondidas cientificamente e, por isso, ficam apenas no campo da especulação.

Salienta-se, primeiramente, que a despeito do intenso debate ao redor do tema, nenhum estudo foi realizado com o objetivo de determinar se a suplementação de creatina afeta a função renal em homens, utilizando-se marcador de função renal padrão-ouro. Tendo em vista a dificuldade de se aplicar o clearance de inulina e diante da imprecisão de marcadores dependentes de creatinina, a busca por métodos mais precisos se faz necessária. Uma das alternativas mais interessantes é a cistatina C. Essa proteína de baixo peso molecular é livremente filtrada pelo glomérulo e reabsorvida, quase que completamente, pelas células do túbulo proximal. A dosagem sérica dessa proteína tem sido proposta como uma excelente medida da taxa de filtração glomerular. Além disso, essa proteína não sofre influência de massa muscular e alimentação, como a creatinina. ${ }^{(29,30)}$. Gualano et al. ${ }^{(31)}$ foram os primeiros a utilizar esse marcador em homens saudáveis suplementados com creatina. Os autores verificaram que a suplementação de creatina em grande dosagem e por um longo período ( 10 g/dia durante 3 meses) não prejudicava a função renal (Figura 1).

Não existem, ao nosso conhecimento, estudos que tenham investigado os efeitos da suplementação de creatina na função renal em sujeitos idosos, crianças e grávidas. Trabalhos que envolvem doenças renais pré-existentes também são escassos e limitam-se ao modelo animal. Dentre estes, nota-se que mesmo os estudos controlados demonstram resultados contraditórios, sugerindo que cada patologia 


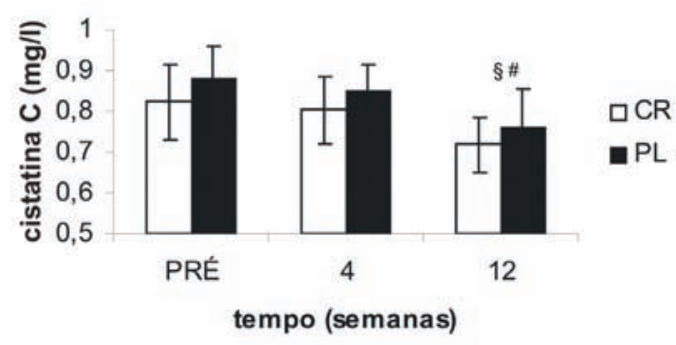

Figura 1. Concentração sanguínea de cistatina $C$ nos grupos $C R(n=7)$ e $P L(n=7)$, no período basal e após 4 e 12 semanas de intervenção. Os sujeitos submetidos a treinamento aeróbio e suplementados com creatina ou placebo apresentaram diminuição significativa nas concentrações de cistatina C ao longo do tempo, sugerindo melhora na função renal. Esse marcador pode ser uma alternativa interessante em pesquisas com suplementação de creatina em humanos. Efeito principal de tempo. $\S 12$ comparado ao $4(p=0,001)$; \# 12 comparado ao PRE $(p=0,001)^{(31)}$.

deva ser investigada particularmente. Enquanto Taes et al. ${ }^{(26)}$, por exemplo, não encontraram prejuízos à função renal em ratos insuficientes renais por modelo 5/6 nefrectomizados, Edmund et al.(28) observaram progressiva deterioração na taxa de filtração glomerular, bem como agravamento de doença renal policística pré-existente. Indivíduos com doenças cardiovasculares e metabólicas, como os diabéticos do tipo 2, por exemplo, também não foram investigados, a despeito de possuírem reconhecida propensão à nefropatia.

Além disso, cabe ressaltar que os consumidores de creatina são, em sua imensa maioria, praticantes de atividade física ou esportistas de alto rendimento. Sendo assim, estudos de maior validade ecológica deverão ser desenvolvidos, a fim de elucidar o papel do exercício físico na função renal de sujeitos suplementados com creatina. Gualano et al.(31) verificaram que sujeitos submetidos a treinamento aeróbio de intensidade moderada (70 \% do VO máx, 3 vezes por semana, 40 minutos ao dia, durante 3 meses) apresentaram melhora na função renal, a despeito da suplementação da creatina em grande quantidade. Estudos adicionais, no entanto, devem verificar os efeitos de diferentes intensidades, volumes e tipos de exercícios físicos sobre a função renal. Por fim, ressalta-se a importância de estudos adicionais com o intuito de investigar a função renal de sujeitos suplementados com creatina por longos períodos e em grande quantidade, já que essa é uma prática comum em academias de ginástica e centros esportivos.

\section{Considerações finais e recomendações}

Mais do que buscar uma resposta à questão genérica: "a creatina prejudica a função renal?", sugere-se o estudo sistemático das situações particulares em que esse suplemento possa ou não incorrer em risco à saúde do consumidor. Apesar da existência de inúmeros relatos de caso na literatura indicando que a creatina possa prejudicar a função renal, não há evidências sustentáveis de que essa substância possa apresentar riscos a homens saudáveis. Pesquisas bem controladas, no entanto, devem investigar sujeitos com doenças renais pré-existentes e com propensão à nefropatia. Recomenda-se a monitoração sistemática nesses consumidores, até que se ateste a segurança da suplementação nesses casos. Aos sujeitos saudáveis que consomem regularmente esse suplemento, sugere-se que não ultrapassem a quantidade de $5 \mathrm{~g} / \mathrm{dia}$, pois não há evidências científicas suficientes que garantam a segurança da ingestão acima dessa dosagem, em longo prazo (para detalhes, ver Shao e Hathcock ${ }^{(32)}$ ). Fornecer essas orientações aos consumidores pode ser uma alternativa prudente e interessante à mera proibição da comercialização do produto, sem respaldo científico adequado.

Todos os autores declararam não haver qualquer potencial conflito de interesses referente a este artigo.

\section{REFERÊNCIAS BIBLIOGRÁFICAS}

1. Wyss M and Kaddurah-Daouk R. Creatine and creatinine metabolism. Physiol Rev 2000; 80: 1107-213.

2. Terjung RL, Clarkson P, Eichner ER, Greenhaff PL, Hespel PJ, Israel RG, et al. American College of Sports Medicine roundtable. The physiological and health effects of oral creatine supplementation. Med Sci Sports Exerc 2000; 32: 706-17.

3. Harris RC, Soderlund Kand Hultman E. Elevation of creatine in resting and exercised muscle of normal subjects by creatine supplementation. Clin Sci (Lond) 1992; 83: 367-74.

4. Ferrante RJ, Andreassen OA, Jenkins BG, Dedeoglu A, Kuemmerle S, Kubilus JK, et al. Neuroprotective effects of creatine in a transgenic mouse model of Huntington's disease. J Neurosci 2000; 20: 4389-97.

5. Pearlman JP and Fielding RA. Creatine monohydrate as a therapeutic aid in muscular dystrophy. Nutr Rev 2006; 64: 80-8.

6. Bender A, Koch W, Elstner M, Schombacher Y, Bender J, Moeschl M, et al. Creatine supplementation in Parkinson disease: a placebo-controlled randomized pilot trial. Neurology 2006; 67: 1262-4

7. Burklen TS, Schlattner U, Homayouni R, Gough K, Rak M, Szeghalmi A, et al. The Creatine Kinase/ Creatine Connection to Alzheimer's Disease: CK-Inactivation, APP-CK Complexes and Focal Creatine Deposits. J Biomed Biotechnol 2006; 2006: 1-11.

8. Gualano B, Novaes RB, Artioli GG, Freire TO, Coelho DF, Scagliusi SR, et al. Effects of creatine supplementation on glucose tolerance and insulin sensitivity in sedentary healthy males undergoing aerobic training. Amino Acids 2007 (in press)

9. Pritchard NR and Kalra PA. Renal dysfunction accompanying oral creatine supplements. Lancet 1998; 351: 1252-3.

10. La créatine dangereuse? L'Equipe 1998; 28

11. Poortmans JR and Francaux M. Adverse effects of creatine supplementation: fact or fiction? Sports Med 2000; 30: 155-70.

12. Kuehl K, Goldberg L and Elliot D. Renal insufficiency after creatine supplementation in a college football athlete. Medicine and Science in Sports and Exercise 1998; 30: S235.

13. Koshy KM, Griswold E and Schneeberger EE. Interstitial nephritis in a patient taking creatine. N Engl J Med 1999; 340: 814-5.

14. Barisic N, Bernert G, Ipsiroglu O, Stromberger C, Muller T, Gruber S, et al. Effects of oral creatine supplementation in a patient with MELAS phenotype and associated nephropathy. Neuropediatrics 2002; 33: 157-61.

15. Revai T, Sapi Z, Benedek S, Kovacs A, Kaszas I, Viranyi M, et al. Severe nephrotic syndrome in a young man taking anabolic steroid and creatine long term. Orv Hetil 2003; 144: 2425-7.

16. Thorsteinsdottir B, Grande JP and Garovic VD. Acute renal failure in a young weight lifter taking multiple food supplements, including creatine monohydrate. J Ren Nutr 2006; 16: 341-5.

17. Holmes FC, Hunt JJ and Sevier TL. Renal injury in sport. Curr Sports Med Rep 2003; 2: 103-9.
18. Patel DR, Torres AD and Greydanus DE. Kidneys and sports. Adolesc Med Clin 2005; 16: 111-9, xi.

19. Poortmans JR, Auquier H, Renaut V, Durussel A, Saugy M and Brisson GR. Effect of short-term creatine supplementation on renal responses in men. Eur J Appl Physiol Occup Physiol 1997; 76: 566-7.

20. Poortmans JR and Francaux M. Long-term oral creatine supplementation does not impair renal function in healthy athletes. Med Sci Sports Exerc 1999; 31: 1108-10.

21. Kuehl K, Goldberg L and Elliot D. Re: Long-term oral creatine supplementation does not impair renal function in healthy athletes. Med Sci Sports Exerc 2000; 32: 248-9.

22. Robinson TM, Sewell DA, Casey A, Steenge G and Greenhaff PL. Dietary creatine supplementation does not affect some haematological indices, or indices of muscle damage and hepatic and renal function. Br J Sports Med 2000; 34: 284-8.

23. Kreider RB, Melton C, Rasmussen CJ, Greenwood M, Lancaster S, Cantler EC, et al. Long-term creatine supplementation does not significantly affect clinical markers of health in athletes. Mol Cell Biochem 2003; 244: 95-104.

24. Groeneveld GJ, Beijer C, Veldink JH, Kalmijn S, Wokke JH and van den Berg LH. Few adverse effects of long-term creatine supplementation in a placebo-controlled trial. Int J Sports Med 2005; 26: 307-13.

25. Poortmans JR, Kumps A, Duez P, Fofonka A, Carpentier A and Francaux M. Effect of oral creatine supplementation on urinary methylamine, formaldehyde, and formate. Med Sci Sports Exerc 2005; 37: 1717-20.

26. Taes YE, Delanghe JR, Wuyts B, van de Voorde J and Lameire NH. Creatine supplementation does not affect kidney function in an animal model with pre-existing renal failure. Nephrol Dial Transplant 2003; 18: 258-64.

27. Ferreira LG, De Toledo Bergamaschi C, Lazaretti-Castro M and Heilberg IP. Effects of creatine supplementation on body composition and renal function in rats. Med Sci Sports Exerc 2005; 37: 1525-9.

28. Edmunds JW, Jayapalan S, DiMarco NM, Saboorian MH and Aukema HM. Creatine supplementation increases renal disease progression in Han:SPRD-cy rats. Am J Kidney Dis 2001; 37: 73-8.

29. Coll E, Botey A, Alvarez L, Poch E, Quinto L, Saurina A, et al. Serum cystatin C as a new marker for noninvasive estimation of glomerular filtration rate and as a marker for early renal impairment. Am J Kidney Dis 2000; 36: 29-34.

30. Delanaye P, Chapelle JP, Gielen J, Krzesinski JM and Rorive G. Cystatin C in the evaluation of renal function. Nephrologie 2003; 24: 457-68.

31. Gualano B, Novaes RB, Shimuzu HM, Artioli GG, Rogeri PS, Ugrinowitsch C, et al. Aerobic training improves renal function and decreases oxidative stress in healthy sedentary males, despite high-dose creatine supplementation. Journal of American Society Nephrology 2006; 17: 203A.

32. Shao A and Hathcock JN. Risk assessment for creatine monohydrate. Regul Toxicol Pharmacol 2006; $45: 242-51$ 